\title{
Atuação da estratégia saúde da família na perspectiva de usuários com câncer
}

\author{
Julia Wakiuchi ${ }^{1}$, Joisy Aparecida Marchi ${ }^{2}$, Sonia Silva Marcon ${ }^{3}$, Catarina Aparecida Sales ${ }^{4}$
}

\author{
${ }^{1}$ Enfermeira, Mestre em Enfermagem. \\ Discente do Programa de Pós-Graduação \\ em Enfermagem, nível Doutorado, da \\ Universidade Estadual de Maringá. \\ Maringá, PR, Brasil. E-mail: \\ julia.wakiuchi@gmail.com. \\ ${ }^{2}$ Enfermeira, Mestre em Enfermagem. \\ Enfermeira da Estratégia Saúde da Família \\ do município de Astorga, PR, Brasil. \\ Astorga, PR, Brasil. E-mail: \\ joisymarchi@hotmail.com. \\ ${ }^{3}$ Enfermeira, Doutora em Enfermagem. \\ Professor Titular da Universidade Estadual \\ de Maringá. Maringá, PR, Brasil. E-mail: \\ soniasilva.marcon@gmail.com. \\ ${ }^{4}$ Enfermeira, Doutora em Enfermagem na \\ Saúde do Adulto. Professor Adjunto da \\ Universidade Estadual de Maringá. \\ Maringá, PR, Brasil. E-mail: \\ casales@uem.br.
}

Recebido: 23/11/2015.

Aceito: 19/07/2016.

Publicado: 01/12/2016

Como citar esse artigo

Wakiuchi J, Marchi JA, Marcon SS, Sales CA. Atuação da estratégia saúde da família na perspectiva de usuários com câncer. Rev. Eletr. Enf. [Internet]. 2016 [acesso em: ____;18:e1184. Disponível em: http://dx.doi.org/10.5216/ree.v18.38612.

\begin{abstract}
RESUMO
Objetivou-se apreender como usuários com câncer percebem a atuação das equipes da Estratégia Saúde da Família. Pesquisa descritiva, de natureza qualitativa, desenvolvida em um município no Noroeste do Paraná. Os dados foram coletados por meio de entrevista semiestruturada junto a nove usuários com câncer cadastrados nas equipes da Estratégia Saúde da Família. Da Análise de Conteúdo Temática emergiram duas categorias, as quais mostram que na percepção dos participantes do estudo o atendimento recebido é pautado na oferta de materiais e insumos, além de condutas clínicas, consideradas imperiosas para o cuidado. Porém, se ressentem pela falta de uma maior atenção e interação com a equipe. Conclui-se que, apesar de os participantes reconhecerem que a assistência recebida inclui o aparato necessário para o acompanhamento de sua doença, percebem a distância no relacionamento com alguns membros da equipe de saúde e a consequente não valorização de suas carências emocionais e subjetividades.

Descritores: Neoplasias; Atenção Primária à Saúde; Satisfação do Paciente; Cuidados de Enfermagem.
\end{abstract}

\section{INTRODUÇÃO}

A presença do câncer nos lares e famílias vem se tornando uma realidade progressiva e evidente no cenário mundial e brasileiro. Nos países em desenvolvimento é esperado que o impacto do câncer na população, chegue a $80 \%$ dentre os 20 milhões de novos casos esperados até $2025^{(1)}$, o que torna inquestionável seu status de problema de saúde pública ${ }^{(2)}$.

O cenário atual do controle do câncer tem se modificado, com grande ênfase no incentivo à prevenção da doença, diagnóstico precoce e na experiência vivenciada pelo usuário durante e após o tratamento ${ }^{(3)}$. 
Nesse interim, a Atenção Primária à Saúde (APS) tem ganhado ênfase por parte de governantes e financiamentos em todo o mundo, sendo concebida como a melhor alternativa de cuidados para a maioria dos casos de promoção e cuidados à saúde, tanto por estabilizar custos, como por assistir ao usuário perto de seu domicílio ${ }^{(3)}$.

No Brasil, a fim de garantir acesso ao usuário com câncer em todos os níveis de atenção do Sistema Único de Saúde foi criada a Política Nacional de Atenção Oncológica, que se encarrega de Ihe afiançar o amparo pela equipe de saúde em suas necessidades durante todo o percurso da doença ${ }^{(4)}$. A APS, em especial a Estratégia da Saúde da Família (ESF), é responsável, dentre outras demandas, por ações direcionadas ao usuário com câncer e aos seus familiares, devendo se fazer presente em todas as fases da doença ${ }^{(5)}$. Apesar de não haver uma sistematização da assistência integral à pessoa com câncer neste nível assistencial, o acompanhamento a esses indivíduos e seus familiares é realizado pela APS por meio de visitas domiciliares (VD), apoio ao cuidador, procedimentos técnicos, consultas e atendimento emocional ao usuário, entre outros $^{(5)}$.

A importância da APS no atendimento ao usuário com câncer é reafirmada, por exemplo, em estudo realizado na Holanda, no qual foi verificado que mulheres com câncer de mama passaram a buscar os serviços da atenção primária duas vezes mais do que anteriormente, a fim de sanar problemas relacionados ao tratamento (efeitos colaterais das terapêuticas) e obter cuidados psicológicos ${ }^{(6)}$.

Vale ressaltar que, a articulação entre serviços de diferentes instâncias assistenciais ainda é precária, principalmente no que tange a comunicação para contrarreferência ${ }^{(5,7-8)}$. Estudo realizado na Dinamarca apontou que, quando a pessoa com câncer inicia seu tratamento, muitas vezes perde o contato com a equipe da atenção primária, o que compromete a comunicação entre equipe generalista e equipe especializada ${ }^{(7)}$. Além disso, a continuidade do cuidado é muitas vezes dificultada pela inexperiência da equipe da atenção primária com relação a abordagem do câncer, resultando em seu não envolvimento nos cuidados ${ }^{(8)}$.

Destarte, os profissionais atuantes na ESF, necessitam estabelecer um relacionamento baseado no vínculo e na corresponsabilização com o ser humano sob sua assistência ${ }^{(9)}$, levando sempre em consideração os desejos e necessidades de usuários e famílias residentes em sua área de abrangência. Deste modo, o olhar do usuário acerca da qualidade da assistência recebida constitui aspecto fundamental para a avaliação dos serviços, pois reflete o vínculo e a horizontalidade do cuidado, além de conferir maior segurança nas ações instituídas ${ }^{(10)}$. Assim, acredita-se que a investigação da satisfação daqueles que utilizam o serviço de saúde pode contribuir para aperfeiçoar a qualidade da assistência ${ }^{(11)}$.

Nessa perspectiva, a proposta deste estudo reforça a necessidade de se compreender as percepções dos usuários com câncer acerca dos cuidados ofertados pelos profissionais da atenção primária. Esse aspecto é fundamental para melhorar a prática cotidiana dos trabalhadores, uma vez que esses devem empenhar-se no reconhecimento das necessidades dos usuários, com enfoque em seus anseios e individualidade.

Assim, este estudo teve como objetivo apreender como usuários com câncer percebem a atuação das equipes da ESF. 


\section{METODOLOGIA}

Estudo descritivo de abordagem qualitativa, realizado junto a usuários com câncer, residentes na área de abrangência das equipes da ESF de uma cidade localizada no noroeste do estado do Paraná. O município conta com 71 equipes da ESF divididas em 29 Unidades Básicas de Saúde (UBS) ${ }^{(12)}$.

Para a presente pesquisa, buscou-se incluir usuários atendidos pelas UBS que possuíam maior número de equipes de ESF, sendo elencadas uma com quatro equipes e, duas com cinco equipes, totalizando 14 equipes abordadas. Em cada uma das equipes foi realizado um levantamento dos usuários com câncer e, posteriormente, foram sorteados os sujeitos que poderiam participar do estudo, um a um.

Os participantes do estudo deveriam ter idade igual ou superior a 18 anos; apresentar condições físicas e preservação do estado cognitivo para responder as perguntas e ter concluído o tratamento antineoplásico ambulatorial ou hospitalar. Depois de identificados os usuários, os Agentes Comunitários de Saúde (ACS) convidaram, de forma gradual, cada um dos sujeitos, verificando com eles se poderiam fornecer endereço e telefone para as pesquisadoras. A partir da concordância, as visitas foram previamente agendadas por telefone.

A coleta de dados foi realizada entre os meses de abril e junho de 2012, nos domicílios dos usuários a partir da questão norteadora: Fale-me sobre o atendimento da Estratégia Saúde da Família durante seu adoecimento por câncer. A análise dos dados foi realizada concomitantemente à pesquisa. A partir do momento em que fatos novos deixaram de surgir e os objetivos do estudo alcançados, a coleta de dados foi finalizada com nove participantes.

As entrevistas foram armazenadas em gravador digital, e posteriormente transcritas na íntegra. A análise dos dados foi guiada pelos passos da Análise de Conteúdo, modalidade Temática ${ }^{(13)}$, que se constituem em: pré-análise, exploração do material e tratamento dos resultados, inferência e interpretação. Ao final, foi realizada a discussão dos dados encontrados buscando relacioná-los com os conceitos de tecnologia de cuidado ${ }^{(14)}$ e a literatura atual sobre o tema.

O desenvolvimento do estudo foi aprovado pelo Comitê Permanente de Ética em Pesquisa com Seres Humanos da Universidade Estadual de Maringá (Parecer no 435/2011). Para garantir o sigilo e anonimato, os usuários estão identificados pela letra S (Sujeitos), seguida de dois números, um indicativo da ordem de realização da entrevista e outro de sua idade. Todos os participantes assinaram o Termo de Consentimento Livre e Esclarecido em duas vias.

\section{RESULTADOS}

Os nove sujeitos em estudo tem idades entre 47 e 74 anos, sendo sete mulheres. Quatro permaneciam em acompanhamento por câncer de mama, duas por câncer de útero, um por câncer de intestino, outro por câncer de próstata e outra por câncer de laringe. De seus relatos emergiram duas categorias, apresentadas a seguir. 
Recebendo um cuidado pautado em saberes e instrumentos: as tecnologias operando a composição do trabalho das equipes

Esta categoria engloba os relatos sobre aspectos que os usuários valorizam em seu tratamento e que foram identificados como relativos às tecnologias leve-duras e duras. Para estas pessoas, a disponibilização de consultas e exames ganha importância ímpar, sendo considerados imprescindíveis para o cuidado:

Então, eles [equipe] têm me auxiliado, assim quando eu estou com alguma dor, a gente vai lá, elas falam com a médica para conseguir algum remédio, a gente toma e vai aliviando [...] todas as vezes que eu preciso de uma guia, de uma consulta, sou atendido. (S3, 62 anos)

[...] foi muito bom. Ele pediu exame, eu fiz os exames, entreguei para ele, ele examinou e, rapidinho, acho que dois meses e pouco, já veio o aviso que minha cirurgia tinha sido marcada. (54, 64 anos)

As falas dos usuários reforçam que, por vezes, o atendimento à saúde é estruturado na resolução de problemas específicos, o que é de grande valia aos que dela necessitam:

[...] tem aqui no posto um salãozinho, que, de mês em mês, eles fornecem o remédio de uso contínuo, e nunca tem faltado! [...], todas as vezes que eu preciso de uma consulta, a gente tem uma, ajuda sim. (S3, 62 anos) [...] encontro com ela [a ACS] na rua e falo que estou precisando de tal remédio, ela anota. Ela é bem prestativa. O material que eu usei para o curativo eles forneceram tudo! Tudo! Tudo! Eles tratam muito bem, é bem equipado. (S4, 64 anos)

Quando questionados acerca da assistência da ESF, os usuários fizeram menção a situações pontuais de atendimento, bem como atrelaram a assistência ao fornecimento de materiais e insumos:

Ah! O que eles [equipe] têm eles me dão, que nem gaze, aquele óleo DERSANI, remédio. Ótimo! (S5, 69 anos) [...] até na época depois da cirurgia que precisei de fraldas, cadeira de banho eles [equipe] me ajudaram, todas essas coisas que eu precisei daqui do postinho eles me arrumaram [..]. (S4, 64 anos)

Então, eu vou lá, peço gaze para fazer o curativo, me dá o soro também, muito bom. (S2, 58 anos);

Me sinto satisfeita! Nossa, dou graças a Deus, porque se não fosse o médico ter adivinhado, descoberto, acho que hoje eu não estaria aqui! (S9, 50 anos)

As tecnologias leves permeando o cuidado ao usuário com câncer

Em oposição aos depoimentos da categoria anterior, um usuário demonstra a necessidade de gestos que remetam ao zelo e a dedicação em prestar os cuidados. A importância de ser lembrado e sentir-se percebido mostram-se preeminentes:

O médico nem olha na cara da gente, isso é bem claro, e eu não estou mentindo, que ele faz isso com todo mundo, não é só comigo. [...] Ele pode pedir todos os exames, a questão é atenção. Ele não me dá atenção. Ele não te olha, não mede sua pressão, não tem assim, aquele contato com o paciente. (S1, 54 anos).

Além disso, alguns usuários ressaltam a importância das tecnologias leves, relatando, por exemplo, o 
valor que atribuem à VD:

O médico da família vinha logo no começo quando eu mudei para cá. Vinha... E nunca mais veio, nem para mim, nem para ela [vizinha]. (S1, 54 anos)

Eu fui fazer o curativo lá no posto, aí eles falaram que tinham que vir aqui em casa fazer esse curativo [...]. Eu saí de lá, fiz o curativo e ela [a enfermeira] não veio falar comigo, então eu deixei para lá. Então, nessa parte, eu acho assim um pouco falho. Faltou! (S6, 59 anos)

Por outro lado, as falas retratam também as atitudes de profissionais que, ao respeitarem as singularidades de cada pessoa, demonstrando empatia e preocupação, tornam-se membros ativos da vida destes sujeitos:

Eles [equipe] me compreendem, por tudo o que eu passei, me atendem bem, quando eu chego lá, principalmente o Dr. "J"., as meninas que me conhecem, todas me atendem bem [...] Às vezes, eles ligam aqui para saber como eu estou, e quando tem consulta que já passou do tempo, eles ligam avisando, então, eles procuram [...] Eles se preocupam com a gente, acho bonito isso, ver a preocupação deles... E eu estou satisfeita com tudo. (S7, 48 anos)

Lá [na UBS] sou bem recebido. Eu fico feliz quando vou lá, fico satisfeito. Elas todas me conhecem, ficam todas alegres, contentes. E lá não falta nada. Elas cuidam muito bem viu! (58, 74 anos)

Diante do sentimento de compaixão e zelo por parte do profissional de saúde, o reconhecimento se faz presente entre os usuários, e se manifesta por meio da valorização de características dos trabalhadores, além de sentimentos de afeto e gratidão:

Desde que eu mudei, eu transferi para cá, são umas mulheres educadas, uns médicos diferentes, sabe, todos tem aquela educação. Então, eu não posso reclamar delas aqui [...] elas tem tanta paciência e calma para explicar as coisas para gente. (S9, 50 anos)

Quando a ACS fica sabendo que eu estou com um problema, ela fala: "Ah, mas vamos tentar resolver para o senhor". É muito bom... Ela é muito boazinha, tadinha [risos], muito boa pessoa. (\$3, 62 anos)

$O$ atendimento ali é muito bom, eu gosto. Todas as pessoas ali me tratam muito bem. Eu já sou até da casa [...]. E minha satisfação é ótima por causa disso, porque eles me ajudam muito. Se não fosse eles me ajudarem, o que seria. (S2, 58 anos)

Bem prestativos sim. Eu tenho só que agradecer, porque é na hora da dor que a gente vê onde é que está o amor [risos]. Tenho eles como da família. (54, 64 anos)

\section{DISCUSSÃO}

Historicamente, a constituição do modelo assistencial para a saúde permaneceu calcada nas tecnologias duras e leve-duras, produzindo uma organização dos serviços com fluxo voltado à consulta médica, em que o saber clínico sobrepõe o trabalho dos demais profissionais e, a produção do cuidado acaba pautada em tais tecnologias ${ }^{(14-15)}$. 
No que tange a atenção à pessoas com câncer, verifica-se que os esforços têm sido direcionados em prol da cura da doença, ou seja, voltados às intervenções altamente tecnológicas centradas no tratamento, o que manteve a APS como marginal nas terapias antineoplásicas ${ }^{(3)}$. Coadunando com tal panorama, o doente com câncer sente-se seguro ante o aparato tecnológico disponibilizado, pois embora o câncer tenha possibilidade de cura quando diagnosticado precocemente, ele convive com a possibilidade de recidiva e metástases, suscitando sentimentos de medo da morte, preconceitos e discriminação social ${ }^{(16)}$.

Nesse sentido, verifica-se a importância do emprego das tecnologias duras e leve-duras para maior acurácia diagnóstica e aperfeiçoamento dos meios de tratamento, sendo constante o desenvolvimento de novos modos de condução terapêutica e modalidades de assistência ${ }^{(17)}$. A utilização da tecnologia, nestas situações, ocorre em um espaço subordinado, no qual a interação entre trabalhador e indivíduo é subsidiada pela realização de procedimentos, e o vínculo passa a ser não com o outro ser humano, mas com um exame, uma consulta ${ }^{(14)}$.

Como revelado nas falas dos participantes, alguns ACS, ao executarem um cuidado pautado nas tecnologias relacionais, acabam, muitas vezes, tendo seu trabalho incorporado no modelo biologicista de intervenção, fazendo referência às tecnologias duras, que não têm potência suficiente para efetivar em sua equipe de saúde uma transição tecnológica. Deste modo, a assistência permanece orientada pelo modelo anterior, aprisionada pelo trabalho morto, instituído e organizado ${ }^{(14)}$.

No espaço domiciliar, os profissionais podem utilizar as tecnologias leves, bem como desenvolver, com maior potência, a sua capacidade criativa para resolver problemas de saúde e, inclusive, interagir melhor com o saber-cuidador da família ${ }^{(14)}$. Contudo, vale ressaltar que, apesar de o ACS ser o trabalhador da APS que mantem maior contato com o usuário em seu domicílio por meio da VD, sua categoria profissional foi evidenciada como a que possui menor experiência anterior de trabalho junto a pessoas com câncer ${ }^{(5)}$, o que poderia limitar suas possibilidades de atuação diante da complexidade das neoplasias e perpetuar a cultura assistencial sanitarista burocrática.

Nesses casos, a dimensão cuidadora da assistência, dentro da lógica hegemônica do modelo médico neoliberal, reduz-se a um papel que não contempla de modo holístico, as necessidades dos usuários, embora nem sempre os mesmos percebam as carências de atenção. Apesar da satisfação demonstrada pelos usuários, é possível identificar que suas expectativas se baseiam na necessidade específica de resolver seu problema de saúde física, porém sem deixar de considerar suas expectativas e sentimentos. Diante disso, percebe-se que, dependendo do momento vivenciado por eles, pode ser necessário valer-se de outras vertentes tecnológicas, com vistas a um atendimento mais integral e resolutivo.

Nesse sentido, alguns relatos mostram as percepções de usuários que desejam um contato individualizado com a equipe de saúde. Para eles, a proximidade e empatia com a equipe podem ter impacto em seu cotidiano e na qualidade de vida por meio de uma atenção diferenciada. Tal perspectiva é amparada pela proposta da ESF em se oferecer atenção à saúde a partir do ambiente físico e social do usuário e sua família, sendo imperioso o emprego de práticas profissionais que extrapolem o âmbito curativo, dispondo 
para tanto, de diferentes recursos tecnológicos ${ }^{(18)}$. Este tipo de trabalho é entendido como tecnologia leve, que constitui relações de interação e subjetividade, e pode estar presente nos modelos de atenção à saúde ${ }^{(14)}$.

Dentro de ações de saúde, na perspectiva da APS, a tecnologia leve faz-se necessária, por ser capaz de extrapolar barreiras e efetivar um cuidado integral. A oferta de um cuidado pautado na integralidade, como atributo essencial da APS, vai ao encontro da necessidade de valorizar as subjetividades do indivíduo, sendo esta a possibilidade máxima de construir intervenções de cuidado centradas no usuário ${ }^{(18)}$. Estas relações possuem extrema importância frente ao cuidado, visto que sua ausência pode acarretar prejuízos na criação de vínculo, acolhimento e responsabilização ${ }^{(15,19)}$.

Para os usuários com câncer, a ausência dos profissionais de saúde em suas casas representa uma lacuna no atendimento de suas necessidades, já que, dentro dos lares, estão presentes todos os percalços e sofrimentos perante a luta contra a doença. Vale ressaltar que, a realização da VD por integrantes da ESF constitui ferramenta imprescindível para superar atitudes de indiferença e pouca interação, consequentemente, confere subsídios para executar as ações que fazem parte da APS ${ }^{(20)}$.

Desse modo, estar presente e ter participação ativa na vida dos indivíduos são ações imperativas em saúde pública, além de demonstrar dedicação aos problemas que eles apresentam. Apesar da cultura dos usuários e sua família se mostrar como centrada no atendimento biomédico, o alcance de seus desejos permanecem aquém do imaginado, levando-os a manifestarem sua insatisfação quanto à prática dos profissionais de saúde, que não desenvolvem por completo aspectos relacionais que envolvem as tecnologias leves, inerentes ao cuidado. Portanto, em seu atendimento, os usuários almejam o uso simultâneo de tecnologias leve-duras, representadas por consultas e exames diagnósticos e de tecnologias leves em seu atendimento, ao demonstrarem a necessidade de gestos que remetam ao zelo e à dedicação em prestar os cuidados.

Um olhar, manifestações de carinho e escuta sensível são pilares da manutenção de afetividade entre profissional e usuário, por qualificarem o atendimento prestado frente as necessidades, fazendo com que a percepção do mesmo seja positiva na presença de tais atitudes. Nessa compreensão, a concretude exclusiva da tecnologia dura é superada, dando espaço para ações que sejam subjetivas ou não, mas que tenham como finalidade o cuidado, por meio de tecnologias leves e leve-duras nos meandros da assistência ${ }^{(5)}$.

A maneira como as relações entre trabalhadores e usuários dos serviços de saúde ocorrem é fundamental para a produção do cuidado. Quando esta relação é pautada no trabalho vivo em ato, ou seja, o trabalhador conta com altos graus de liberdade, podendo exercer melhor a criatividade necessária ao cuidado em saúde e fortalecer os aspectos relacionais do seu trabalho ${ }^{(14)}$, promove-se a abertura para o encontro da produção do cuidado que atenda às reais expectativas dos usuários.

O que determina se uma tecnologia desumaniza e objetifica o cuidado não é só a tecnologia em si, mas, sobretudo, como estas ocorrem ou são empregadas no contexto da assistência ${ }^{(10)}$. Para superar o modelo médico hegemônico existente, faz-se necessário o gerenciamento das organizações de saúde de 
modo mais coletivo, com uma restruturação coerente e com ações em saúde voltadas para uma lógica "usuário-centrada", ou seja, pautada na constituição de vínculos e no atendimento das necessidades individuais e coletivas ${ }^{(15)}$.

\section{CONSIDERAÇÕES FINAIS}

Diante dos resultados do presente estudo, verificou-se que o emprego das tecnologias duras e leveduras em prol da cura do câncer tem sua relevância, porém fica expresso que os participantes almejam uma atuação da ESF usuário-centrada, pautada em tecnologias leves, pois demonstram a necessidade que sentem de atitudes que reportem ao zelo e à dedicação dos profissionais na prestação dos cuidados.

Nessa perspectiva, para os usuários se faz essencial a presença de aparatos que auxiliem o diagnóstico e tratamento, além da disponibilização de insumos materiais que supram suas demandas. A tecnologia levedura, portanto, deve permear a assistência à saúde como um todo, por meio da associação entre conhecimento científico e responsabilidade do profissional junto as pessoas a serem cuidadas. Mais que isso, neste contexto, o emprego correto de tecnologias leves constitui ao mesmo tempo, ferramenta e estratégia capaz de promover uma assistência holística aos usuários com câncer, permitindo que estas pessoas sejam amparadas e não se sintam sós no enfrentamento de sua condição de saúde.

Nesse sentido, o cuidado integral e empático a pessoa com câncer, especialmente quando prestado em seu lar, caracteriza-se como desafio que permeia a assistência prestada no âmbito da ESF. Desta forma, os profissionais de saúde, em especial os integrantes da equipe de enfermagem, poderão estar mais presentes na vida cotidiana dos usuários, e obter subsídios para promover ações integrais, e que efetivamente os auxiliem, bem como sua família no enfrentamento do câncer.

Ainda permanecem lacunas no que tange à assistência às reais necessidades do indivíduo e sua família. No entanto, os resultados deste estudo podem conferir subsídios para todos aqueles que atuam na ESF e, para todos os profissionais de enfermagem que permanecem junto a pessoa em tratamento oncológico, com vistas a fazê-los refletir, continuamente, acerca das tecnologias que estão sendo utilizadas em seu processo de trabalho e, mais ainda, a fim de que possam identificar os pontos frágeis de sua própria atuação.

\section{REFERÊNCIAS}

1. Stewart BW, Wild CP , editores. World Cancer Report: 2014. Lyon: IARC; 2014.

2. Rosas MSL, Silva BNM, Pinto RGM, Silva BV, Silva RA, Guerra LR, et al. Incidência do câncer no Brasil e potencial uso dos derivados de Isatinas na cancerologia experimental. Revista Virtual de Química. 2013;5(2):243-265.

3. Rubin et al. The expanding role of primary care in cancer control. The Lancet Oncology. 2015;16(2):1231-1272.

4. Ministério da Saúde. Portaria no874, de 16 de maio de 2013. Institui a Política Nacional para a Prevenção e Controle do Câncer na Rede de Atenção à Saúde das Pessoas com Doenças Crônicas no âmbito do Sistema Único de Saúde (SUS) [Internet]. Brasília: Diário Oficial da União, 2013. [acesso em 15 nov 2015]. Disponível em: http://bvsms.saude.gov.br/bvs/saudelegis/gm/2013/prt0874_16 05 2013.html.

5. Simino GPR, Santos CB, Mishima SM. Acompanhamento de usuários, portadores de câncer, por trabalhadores da saúde da família. Rev. latinoam. enferm. [Internet]. 2010 [acesso em: 15 nov 2015]; 18(5): [09 telas]. Disponível em: 


\section{http://www.scielo.br/pdf/rlae/v18n5/pt 04.pdf}

6. Roorda C, de Bock GH, van der Veen WJ, Lindeman A, Jansen L, van der Meer K. Role of the general practitioner during the active breast cancer treatment phase: an analysis of health care use. Support Care Cancer. 2012;20(4):70514

7. Dalsted RJ, Guassora AD, Thorsen T. Danish general practitioners only play a minor role in the coordination of cancer treatment. Dan Med Bull. 2011;58(1):A4222.

8. Hudson SV, Miller SM, Hemler J, Ferrante JM, Lyle J, Oeffinger KC, et al. Adult cancer survivors discuss follow-up in primary care: 'not what i want, but maybe what i need'. Ann Fam Med. 2012;10(5):418-27.

9. Silva MM, Budó MLD, Resta DG, Silva SO, Ebling SBD, Carvalho SORM. Integralidade na saúde da família: limites e possibilidades na perspectiva da equipe. Ciênc. cuid. saude. 2013;12(1):155-63

10. Savassi LCM. A satisfação do usuário e a autopercepção da saúde em atenção primária. Rev. bras. med. fam. comunidade. 2010;5(17):3-5.

11. Moraes VD, Campos CEA, Brandão AL. Estudo sobre dimensões da avaliação da Estratégia Saúde da Família pela perspectiva do usuário. Physis. 2014;24(1):127-146.

12. Ministério da Saúde. Secretaria de Atenção à Saúde. CNESNet [Internet]. Consultas - Equipes. [acesso em: 15 nov 2015]. Disponível em: http://cnes2.datasus.gov.br/Lista_Tot_Equipes.asp

13. Minayo MCS. O desafio do conhecimento: pesquisa qualitativa em saúde. 12a ed. São Paulo: Hucitec; 2010.

14. Franco TB, Merhy EE. Cartografias do Trabalho e Cuidado em Saúde. Tempus. 2012;6(2):151-63.

15. Merhy EE. Saúde: cartografia do trabalho vivo em ato. 3a ed. São Paulo: Hucitec; 2002.

16. Salci MA, Marcon SS. A convivência com o fantasma do câncer. Rev. gaúch. enferm. 2010;31(1):18-25.

17. Silva RCV, Cruz EA. Planejamento da assistência de enfermagem ao paciente com câncer: Reflexão teórica sobre as dimensões sociais. Esc. Anna Nery Rev. Enferm. 2011;15(1):180-5.

18. Oliveira MAC, Pereira IC. Atributos essenciais da Atenção Primária e a Estratégia Saúde da Família. Rev Bras Enferm. 2013;66(esp):158-64.

19. Abrahão-Curvo A. Avaliação da atenção básica em saúde destacando satisfação e insatisfação na perspectiva dos usuários, com ênfase na integralidade da atenção [dissertação]. Ribeirão Preto (SP): Escola de Enfermagem de Ribeirão Preto; 2010. 153 p.

20. Eufrásio RG, Alcântara Júnior JE, Araújo LR, Negreiros MAM. Detecção precoce de carcinoma basocelular: importância da visita domiciliar no contexto da Atenção Integral à Saúde do idoso. Rev. APS. 2010;13(2):241-44. 